\title{
THE INFLUENCE OF THE TRAFFIC COMPOSITION ON THE DEGREE OF ENVIRONMENTAL POLLUTION AND THE WAYS OF PREVENTION
}

\author{
Giorgi Purtskhvanidze, Professor
}

Akaki Tsereteli State University

DOI: https://doi.org/10.31435/rsglobal_ejits/30112018/6218

\section{ARTICLE INFO}

Received 21 July 2018

Accepted 20 November 2018

Published 30 November 2018

\section{KEYWORDS}

traffic flow, ecology, transport, automated motion control system.

Citation: Giorgi Purtskhvanidze. (2018) The Influence of the Traffic Composition on the Degree of Environmental Pollution and the Ways of Prevention. European Journal of Intelligent Transportation Systems. 1(1). doi: 10.31435/rsglobal_ejits/30112018/6218

Copyright: (C) 2018 Giorgi Purtskhvanidze. This is an open-access article distributed under the terms of the Creative Commons Attribution License (CC BY). The use, distribution or reproduction in other forums is permitted, provided the original author(s) or licensor are credited and that the original publication in this journal is cited, in accordance with accepted academic practice. No use, distribution or reproduction is permitted which does not comply with these terms.

The ecological condition of atmospheric air is the most important problem of the modern society, because there exist various factors, which condition the pollution of environment with toxic substances.

Motor transport is an important part of the energy sector and represent one of the main sources of polluting the atmospheric air, because the harmful toxic compounds emitted and acoustic energy radiated during the working process of auto transport causes the collapse of the ecological balance of the atmosphere. Nowadays, it represents one of the main sources of polluting air with greenhouses gases. Therefore, a special attention is paid to the events for the control and reduction of the emissions from transport in a lot of countries of the world.

The degree of harmful impact of motor transport on the local environment atmosphere is determined by such factors as the intensity and volume of emitted hazardous substances, area of territory being polluted, the degree of technogenic adoption of the region and etc.

Movement of a single car on the motorway can't have a significant impact on the environment and ecosystem. But when the traffic flow is discussed under the conditions of load and passenger transportation, the deterioration of quality indicators of the city air is caused by: the sharp increase of the number of transport means, overload of highways, the geometric characteristics of road nets, quality of traffic regulation, irrational distribution of traffic flow, qualification of the drivers, road surface and the technical condition of auto park, composition of the traffic.

Pollution degree of transportation means in the city conditions is mainly determined by the following regimes of the motion: speeding-up, work during idle motion, motion with established speed and slowing down. The duration of each phase and the volume of the toxic substances exhaled is different, respectively, during the whole period of the motion. 
The basic factor for determining the pollution of the environment by the traffic is the composition, the pattern of road net, intensity of the traffic. Two approach can be used in order to evaluate the harmful substances emitted in the atmosphere by the traffic: 1) without considering the effect of vehicles on each other; 2) considering the effect of the transport means on each other. In the first case, the compounds emitted by each of transport means are directly summed up. While, in the second case, actions of each driver and motion, as the unity of each vehicle, are considered.

When estimating the concentration of the harmful substances exhaled in the atmosphere by the traffic we calculate the following measures: 1) determine the fuel consumption and of each transport means of the traffic flow and the amount of the exhaled harmful compounds during the motion on different speed; 2) determine the fuel consumption and amount of the exhaled harmful compounds of the traffic on the separate section of the road network; 3) determine the concentration of the exhaled harmful substances on the section of highway under discussion.

The amount of the exhaled harmful compounds on the highways by the transport means flow is determined using the following formula:

$$
Y=\sum_{i} \sum_{j K} W_{j} P_{K i} N_{a}
$$

Where $W_{j}$ - is amount of any exhaled component during the driving period, $\mathrm{g} / \mathrm{km}$;

$P_{K i}-$ is the probability of falling in diapason of i speed in the traffic for $\mathrm{K}$ group transportation means;

$N_{a}-$ is intensity of the traffic, car/h.

The rapid growth of automobile park in Georgia caused the significant increase of intensity of the traffic motion on the main highways of the cities', which conditioned the deterioration of the ecological condition of the county.

Fig. 1 displays the results of the research conducted by us, how the amount of carbon oxide (CO) exhaled by the traffic on the roads and junctions of the road, depending on the traffic composition and intensity of the motion. As known, in the cities, the main factor of polluting the air with carbon oxide is motor transport. The analysis shows, that amount of toxic substances exhaled on crossroads is 5-8 times more compared to the riding sections of the road, and the reduction of the share of truck vehicles in the traffic on the motorway districts causes reduction of atmosphere pollution to $40 \%$.
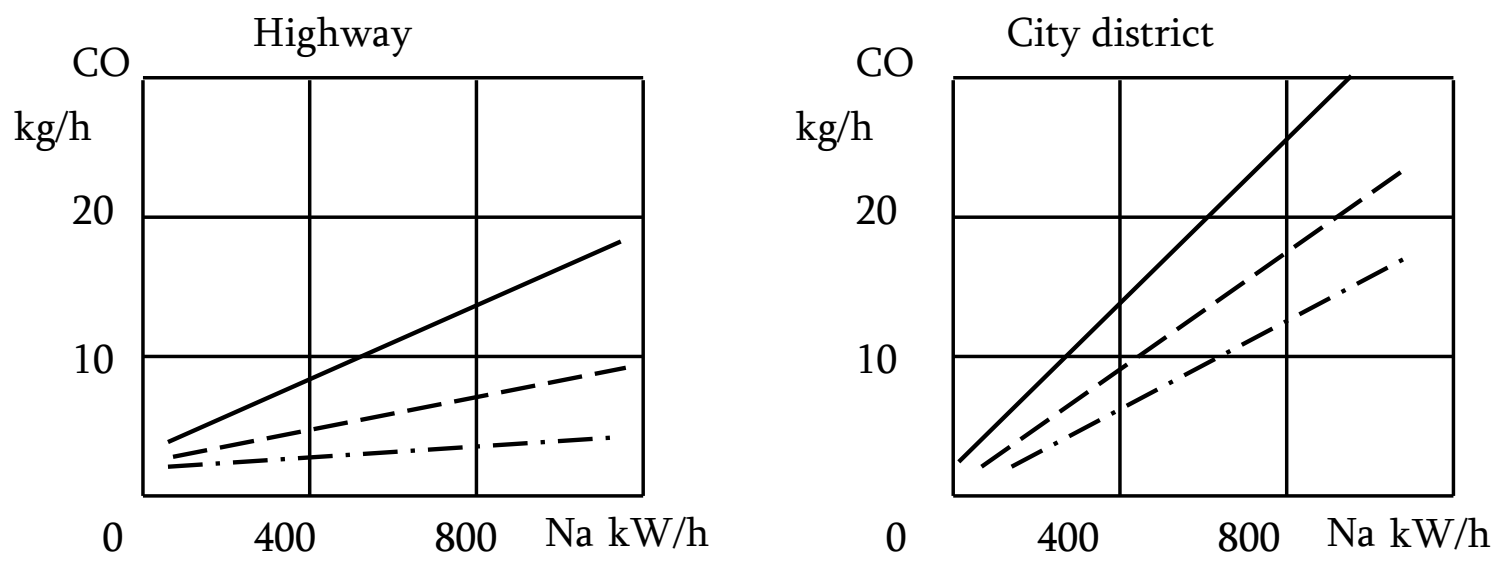

Fig 1. Relationship of amount of toxic substances with the composition of traffic flow. Composition: light/truck/bus, \%.

50/40/10; _ _ _ 75/20/5; . . . . 95/0/5. 
In order to the amount of hazardous toxic substances on city crossroads and highways it's essential to implement the automatized management system, which consists of the following main parts: hardware maintenance, technical maintenance, software maintenance.

The modern automatized systems of traffic management consider the automatization of data collection, transfer of information, processing the received data, working out the management decisions and proactive management of road cases by means of these decisions.

The implementation of automatized system "Green Street" in Kutaisi is practicable on Chavchavadze Avenue. With the purpose of introducing coordinative traffic management systems on Chavchavadze Avenue the study traffic flow parameters had been conducted on stationary positions by the method of natural research. The experimental research had been conducted contemporaneously for each main direction of every crossroad of the Avenue.

Fig. 2 displays the curves of regularities of motion intensity changes, with evident unevenness of minimum and maximum points during the day, obtained as research results on one of the crossroads of Chavchavadze Avenue. Reasonable and limiting measures of traffic parameters had been established for practical purposes with sufficient precision, during any day of the week, for the change of coordination program.

The results of experimental study revealed, that geometrical parameters of crossroads of Chavchavadze Avenue and riding sections on them with the parameters of traffic flow satisfies the main conditions of implementing the automatized traffic management system "Green Street" on them. Automatized system of traffic management will serve the following crossroads of Chavchavadze Avenue simultaneously: The crossroad in front of station "Kutaisi - II"; cross of Chavchavadze and Liberty streets; crossroad in front of Youth Park; cross of Chavchavadze-Ninoshvili-Gamsakhurdia streets; cross of Chavchavadze-AsatianiNikea streets.

The analysis of traffic functioning showed, that after the implementation of the automatized systems of traffic management following effectiveness of traffic organization will take place: traffic-light;

- The delays of the traffic reduce by $30-35 \%$ as the result of optimizing the regimes of

- As the result of shortening the length of the row of the vehicles waiting for the traffic signal allowing them to start the motion on the road between the crossroads, the average speed of the traffic increases by $10-15 \%$;

- Travel time reduces by $10-12 \%$;

- As the result of reduced amount of exhaled gases by the engine the ecological condition of the city improves by $20-25 \%$. 


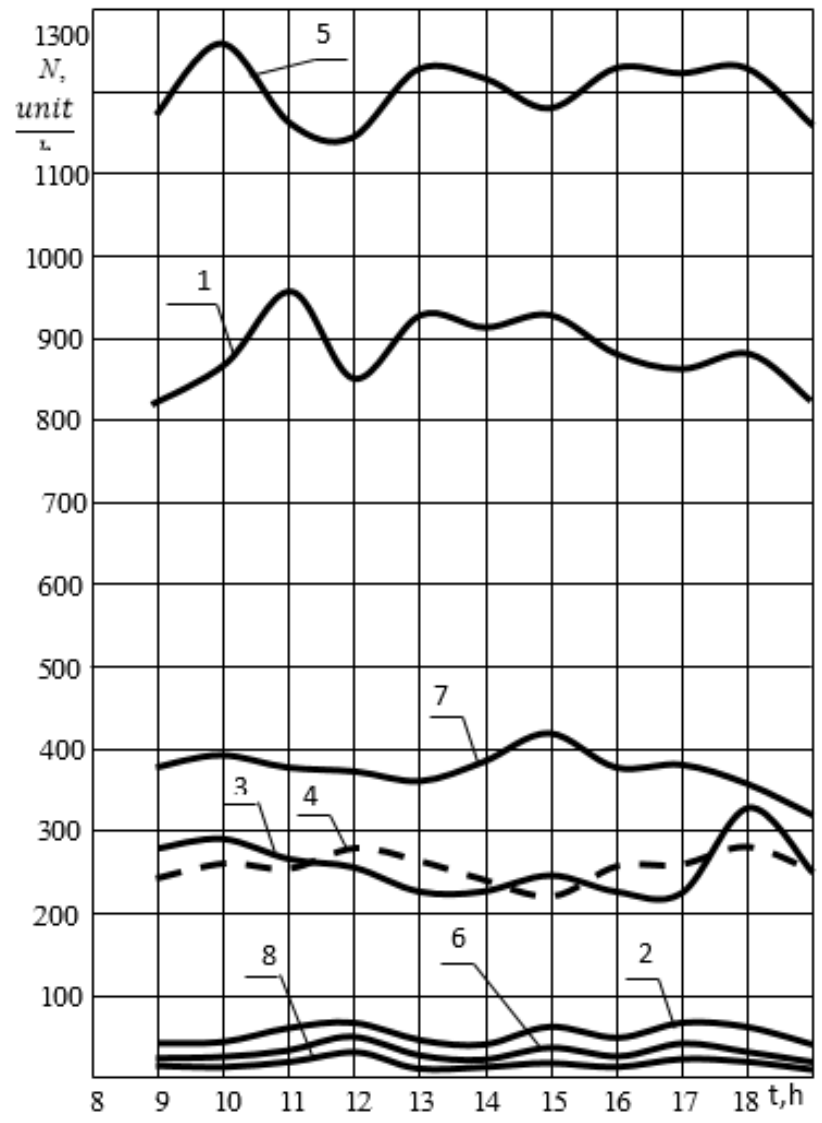

Fig. 2. The curves of traffic intensity changes during the day on the crossroad in front of the station "Kutaisi II" according the directions of the motion

\section{REFERENCES}

1. Kochiashvili I., Kvirikashvili D. - Technical means of organizing the traffic, Tbilisi, 1997, 240pg.

2. Kochiashvili I., Kvirikashvili D. Gelashvili O. - Organization of traffic, Tbilisi, 1999, 248pg.

3. Inose H., Hamada T. Road traffic management. Under the Edition of. M. I. Blinnikova: Translation from English. M.: Transport, 1983. - 284 p.

4. Lukanin V. N, Tropimenko I. V. Industrial-transport ecology. M.: High School, 2001. - 273 p. 